\title{
Meningkatkan Kualitas Pembelajaran pada Fakultas Pertanian Unsyiah Melalui Peningkatan Efektivitas Pemanfaatan E-Learning
}

\author{
${ }^{1}$ Allaily Tarman*), ${ }^{1}$ Cut Nilda, ${ }^{1}$ Yuliani Aisyah, ${ }^{1}$ Bakhtiar Bakhtiar, \& ${ }^{1}$ Rahmaddiansyah Rahmaddiansyah \\ 1Fakultas Pertanian Universitas Syiah Kuala Banda Aceh
}

(allaily@unsyiah.ac.id)*)

\begin{abstract}
Abstrak
Riset aksi ini bertujuan mengetahui pemanfaatan sistem e learning dan peningkatan pemanfaatannya di Fakultas Pertanian Unsyiah. Riset dibagi dalam beberapa tahapan yaitu survey, focus group discussion (FGD), pelatihan dan pendampingan. Riset aksi ini dilakukan selama 9 bulan di Fakultas Pertanian Unsyiah, oleh tim Satuan Jaminan Mutu Fakultas (SJMF) dan Tim Penjaminan Mutu Akademik Jurusan (TPMA) di Fakultas Pertanian kepada dosen di Fakultas Pertanian Unsyiah. Riset dilakukan pada 20 orang dosen dan Data yang diperoleh dianalisis deskriptif. Hasil survey menunjukkan bahwa mayoritas responden menjawab elearning dapat membantu dosen untuk sharing info kepada mahasiswa termasuk bahan kuliah, mengadakan kuis dan ujian secara online. Tahap kedua menghasilkan bahwa pelatihan sudah pernah diikuti tetapi belum ada pendampingan dan perlu pelatihan kembali, pelatihan diharapkan diadakan secara berkala, perlu adanya tim Informasi dan Teknologi (IT) khusus di tingkat fakultas. Tahapan terakhir menghasilkan bahwa pelatihan dan pendampingan perlu sampai akhir semester, dengan total peningkatan sementara dari pelatihan adalah dari 25 mata kuliah pada semester genap 2017/2018 (hanya 6 dosen sebagai pemanfaat) menjadi berjumlah 75 matakuliah (yang diasuh oleh 50 dosen yaitu $25 \%$ dari keseluruhan dosen di Fakultas Pertanian) di semester ganjil 2018/2019. Kesimpulannya bahwa dari riset aksi ini adalah jumlah dosen pemanfaat sistem e learning meningkat dengan adanya pelatihan berkala, dan pendampingan.
\end{abstract}

Kata Kunci: e learning; model; mutu; pembelajaran; sistem

\section{Pendahuluan}

Riset aksi ini dilakukan untuk mengetahui masalah yang melatarbelakangi kurangnya pemanfaatan e-learning di Fakultas Pertanian Universitas Syiah Kuala. E-learning merupakan model pembelajaran yang berbasis internet dengan memanfaatkan teknologi komputer dan jaringan internet. Sistem e-learning yang dikelola oleh Unit Pelaksana Teknis Teknologi Informasi dan Komunikasi (UPT TIK) di Universitas Syiah Kuala termasuk pada Fakultas Pertanian sudah tertata dengan baik, namun pemanfaatannya masih sangat kurang.
Proses pembelajaran e-learning sesuai dengan program nasional sebagai upaya peningkatan kualitas sekaligus efisiensi proses belajar mengajar untuk menghadapi tantangan dan mengikuti perkembangan zaman pada era digital. Pedoman penyelenggaraan program elearning secara jelas telah tertuang dalam Peraturan Rektor Universitas Syiah Kuala No 1 Tahun 2018 [1]. Pedoman ini dibuat berdasarkan Peraturan Menteri Riset, Teknologi dan Pendidikan Tinggi Republik Indonesia Nomor 44 Tahun 2015 tentang Standar Nasional Perguruan Tinggi, pada Bagian keempat : Standar Proses Pembelajaran, di dalam pasal 14 ayat 2 dan 3 terkait dengan proses pembelajaran dan metode pembelajaran [2]. Hal ini juga sesuai dengan Renstra Unsyiah Tahun 2015-2019 yaitu salah satu dari 4 (empat) sasaran strategis Renstra Unsyiah adalah meningkatnya kualitas pembelajaran, dengan arah kebijakannya menyediakan layanan pendidikan yang bermutu dan relevan melalui strategi pengembangan memperpendek masa studi dan meningkatkan rata-rata IPK Iulusan [3].

Sasaran kegiatan dari Renstra Unsyiah adalah peningkatan layanan Tridarma Perguruan Tinggi, dengan output 1 adalah layanan pembelajaran, dengan indikator kinerja kegiatan : target jumlah kegiatan pemanfaatan e-learning (IKK 1.8) pada Tahun 2018 sebanyak 19 kegiatan . Berdasarkan sasaran tersebut, maka sejak tahun 2016 sistem e-learning di Unsyiah telah dibuat dengan situs pembelajaran URL: www.elearning.unsyiah.ac.id dengan berbagai kelengkapannya oleh Unit Pelaksana Teknis Teknologi Informasi dan Komunikasi (UPT TIK) Unsyiah. Sedangkan cikal bakal e-learning di Unsyiah telah dimulai sejak setelah tsunami yaitu tahun 2008 oleh Unit Pelaksana Teknis Pusat Komputer dan Sistem Informasi (UPT PUKSI). Berdasarkan Peraturan Menteri Riset, Teknologi dan Pendidikan nomor 48 tahun 2015, tentang Organisasi dan Tata Kelola maka UPT PUKSI diubah menjadi UPT TIK. Namun hasil monitoring dan evaluasi oleh Pusat Pengembangan Pembelajaran (PIJAR) pada tahun 2017 melalui pengamatan sampling atas 24 program studi di Unsyiah, tingkat pemanfaatan e learning menunjukkan data yang masih sangat rendah 
yaitu berada di bawah angka 40\%. Selanjutnya, data mata kuliah yang menyelenggarakan e learning pada semester genap 2017/2018 di Unsyiah sebanyak 182 mata kuliah/kelas dari total 5202 mata kuliah/kelas sehingga hanya mencapai 3,49\%, sedangkan Fakultas Pertanian pemanfaatan e learning hanya ada 25 mata kuliah/kelas atau hanya mencapai 0,14 \% [4]. Temuan ini mendasari penelitian riset aksi ini sehingga ditindaklanjuti untuk menjawab alasan kecilnya persentase pemanfaatan e-learning. Motivasi siswa dan dukungan akademik untuk menggunakan sistem e learning cukup baik, namun karena kecilnya penggunaan sistem oleh dosen menjadikan linier dengan jumlah mahasiswa yang menggunakan sistem ini. Fokus riset ini adalah untuk memanfaatkan e-learning sebagai salah satu model pembelajaran sehingga kegiatan pembelajaran dapat berjalan secara efektif dan efisien, serta menjawab tantangan zaman.

\section{Diskusi}

\section{A. Survey}

Pada tahap ini ditanyakan tentang informasi awal yang dimiliki oleh peserta survei terhadap media e-learning. Pertanyaan pada tahap ini adalah (1) Apakah bapak/ibu mengetahui media pembelajaran elearning?, (2) Jika tahu dari mana ibu mendapatkan informasi ?, (3) Apakah media pembelajaran elearning bermanfaat jika digunakan dalam proses belajar mengajar.

Hasil survey menunjukkan bahwa 100\% peserta mengetahui tentang E-learning. Peserta mendapat informasi tentang e-learning dari sosialisasi dan pelatihan yang dilaksanakan oleh fakultas dan juga universitas (65\%), media informasi (35\%)dan pengalaman menggunakan elearning pada saat studi (15\%). Dari jumlah tersebut, secara umum 50 persen (10 orang dosen) menganggap e-learning bermanfaat dalam prose belajar mengajar dan 50\% menganggap elearning sangat bermanfaat dalam proses pembelajaran. Mayoritas responden menjawab elearning dapat membantu dosen untuk sharing info kepada mahasiswa termasuk bahan kuliah, mengadakan kuis dan ujian secara online.

Hasil survey ini sejalan dengan hasil penelitian lainnya yang menyatakan e learning efektif menjadi media pembelajaran pada sekolah menengah kejuruan telekomunikasi di Purwokerto dengan tingkat kecenderungan 77,27\% [5]. Lebih lanjut lagi dijelaskan bahwa komitmen sekolah belum cukup sehingga membuat urgensi pemanfaatan sistem pembelajaran e learning menjadi tidak optimal.
Tabel 2. Isi Pertanyaan dalam Quisioner beserta Jawaban Responden

\begin{tabular}{|c|c|c|c|c|}
\hline $\begin{array}{l}\mathrm{N} \\
\mathrm{O}\end{array}$ & Pertanyaaan & $\begin{array}{l}\text { Tidak } \\
\text { setuju }\end{array}$ & Setuju & $\begin{array}{l}\text { Sangat } \\
\text { setuju }\end{array}$ \\
\hline 1. & $\begin{array}{l}\text { E-learning } \\
\text { memudahkan } \\
\text { dosen dalam } \\
\text { mendistribusikan } \\
\text { materi perkuliahan }\end{array}$ & & $30 \%$ & $70 \%$ \\
\hline 2. & $\begin{array}{l}\text { E-learning } \\
\text { mengurangi } \\
\text { pemanfaatan } \\
\text { kertas }\end{array}$ & $5 \%$ & $20 \%$ & $75 \%$ \\
\hline 3. & $\begin{array}{l}\text { E-learning } \\
\text { memudahkan } \\
\text { mengontrol tugas } \\
\text { yang dikumpulkan } \\
\text { oleh mahasiswa }\end{array}$ & & $45 \%$ & $55 \%$ \\
\hline 4. & $\begin{array}{l}\text { E-learning } \\
\text { memudahkan } \\
\text { dosen untuk } \\
\text { memberi tugas }\end{array}$ & & $45 \%$ & $55 \%$ \\
\hline 5. & $\begin{array}{l}\text { Dosen lebih mudah } \\
\text { dalam } \\
\text { medokumentasika } \\
\text { n materi } \\
\text { pembelajaran, } \\
\text { tugas dan kuis }\end{array}$ & & $35 \%$ & $65 \%$ \\
\hline 6. & $\begin{array}{l}\text { E-learning } \\
\text { membantu } \\
\text { transparansi dalam } \\
\text { pemberian nilai }\end{array}$ & & $50 \%$ & $50 \%$ \\
\hline 7. & $\begin{array}{l}\text { E-learning } \\
\text { memudahkan } \\
\text { untuk berdiskusi di } \\
\text { luar jam mengajar } \\
\text { bersama } \\
\text { mahasiswa dan tim } \\
\text { pengajar }\end{array}$ & $5 \%$ & $45 \%$ & $50 \%$ \\
\hline 8. & $\begin{array}{l}\text { E-learning } \\
\text { membantu } \\
\text { memperkaya } \\
\text { wawasan } \\
\text { mahasiswa }\end{array}$ & $5 \%$ & $60 \%$ & $35 \%$ \\
\hline 9. & $\begin{array}{l}\text { E-learning } \\
\text { membantu } \\
\text { menghemat waktu } \\
\text { dan tempat }\end{array}$ & $5 \%$ & $30 \%$ & $65 \%$ \\
\hline $\begin{array}{l}1 \\
0 .\end{array}$ & $\begin{array}{l}\text { Sudah saatnya } \\
\text { untuk } \\
\text { memanfaatkan E- } \\
\text { learning karena } \\
\text { sesuai dengan } \\
\text { perkembangan } \\
\text { zaman } \\
\end{array}$ & & $35 \%$ & $65 \%$ \\
\hline
\end{tabular}

Keterangan : Jumlah responden 20 orang dosen Fakultas Pertanian Universitas Syiah Kuala.

Pada sesi ini pertanyaan yang diajukan adalah (1) Apakah bapak/ibu saat ini menggunakankan media pembelajaran elearning?, 
(2) Jika belum pernah menggunakan elearning apa alasan bapak/ibu? dan (3) Saran agar Dosen FakultasPertanian termotivasi menggunakan elearning. Berdasarkan pertanyaan-pertanyaan di atas, mayoritas responden (55\%) belum menggunakan e-learning, sedangkan 40\% lainnya pernah menggunakan e-learning pada mata kuliah tertentu dan hanya $5 \%$ responden yang menggunakan e-learning di semua mata kuliah yang diasuhnya. Alasan rendahnya penggunaan elearning dari responden dapat dilihat pada grafik di bawah ini.

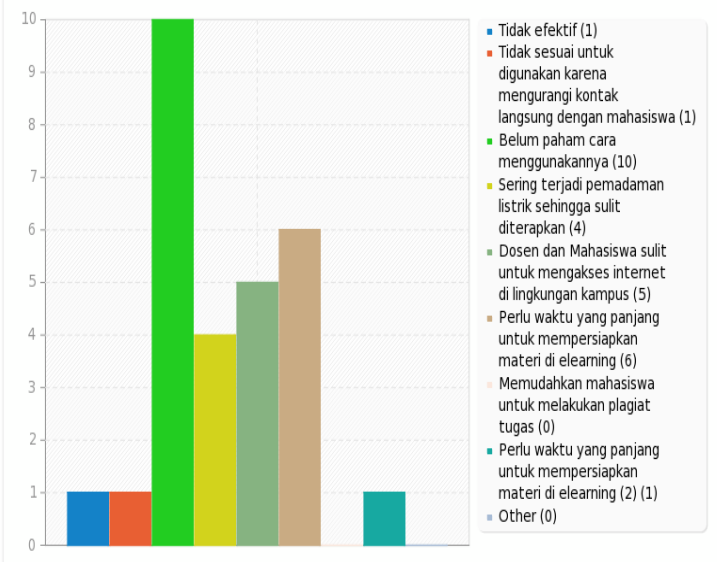

Gambar 1. Grafik Alasan Responden dalam Penggunaan E Learning.

Berdasarkan grafik di atas, 50\% responden menjawab belum paham cara menggunakan e-learning sementara yang lainnya berpendapat kesulitas mengakses internet di lingkungan kampus, perlu waktu persiapan yang panjang dan seringnya terjadi pemadaman listrik. Dari hasil survey ini dapat disimpulkan bahwa $e$ learning masih perlu dilatih penggunaannya serta peningkatan sarana dan prasarana teknologi informasi terkait. Oleh karena itu rekomendasi yang dapat dirumuskan adalah adanya pelatihan secara berkala dan penguatan sarana skaligus prasarana IT.

E learning merupakan tantangan dan sekaligus kemudahan dalam proses pembelajaran pada era global [6]. Pesatnya perkembangan teknologi dan informasi menuntut dunia pendidikan menggunakan inovasi dalam hal pembelajaran [7].

\section{B. Focus Group Discussion (FGD)}

Kegiatan ini dilakukan selama setengah hari, menampung segala tanggapan dosen tentang $e$ leaning. Adapun beberapa hal yang dapat disarikan dari pertemuan FGD adalah sebagai berikut, yaitu pada Tabel 3 .
Tabel 3. Permasalahan dan saran yang terkumpul saat FGD

\begin{tabular}{|l|}
\hline Permasalahan \\
\hline 1. Sebagian peserta sudah pernah ikut pelatihan tetapi \\
masih belum mampu mengaplikasikan e-learning
\end{tabular} dalam proses pembelajaran.

2. Sosialisasi e-learning untuk dosen dan mahasiswa masih kurang sehingga sebagian dosen dan mahasiswa tidak tahu tentang e-learning

3. Kurangnya sosialisasi tentang manfaat dari elearning, termasuk cara pembuatan video, tugas, diskusi interaktif. Penggunaan hanya sebatas mengupload bahan kuliah

4. Apabila dosen mengajar dalam tim, tidak semua anggota tim pengajar paham tentang e-learning, system perkuliahan yang menggunakan e-learning.

5. Dengan penerapan e-learning maka tidak terjadi kontak dosen dengan mahasiswa dan dikhawatirkan mahasiswa tidak mengerti apa yang disampaikan dosen melalui e-learning sehingga sebagian dosen lebih memilih tatap muka langsung dalam proses pembelajaran.

6. Mahasiswa dapat mengerjakan tugas dan ujian secara bersama-sama, pengawasan kurang

7. Fasilitas listrik dan internet yang kurang memadai.

Saran-Saran

Kecepatan internet agar ditingkatkan

2. Tidak semua dosen familiar dengan website kampus

3. Perlu pelatihan dan pendampingan berkelanjutan

4. Adanya penghargaan bagi dosen yang menggunakan e learnning

5. Dilakukan sosialisasi dan pelatihan tentang pembuatan materi kuliah secara E learning dan kiatkiat dalam pelaksanaan kuliah secara $E$ learning yang baik dan benar.

6. Perlunya peningkatan sarana dan sarana pendukung, dan perlu juga pemahaman bahwa proses pendidikan yang baik adalah yang tetap melibatkan proses konvensional tatap muka sehingga program pembelajaran kombinasi dapat dilaksanakan.

7. Adanya prosedur yang jelas.

8. Perlu tim asistensi untuk percepatan program tersebut, sekalian ada reward nya Diwajibkan, diberikan reward dengan pengelolaan e-learning terhadap mata kuliah tertentu yang menarik.

Para peserta sangat antusias terhadap e learning karena dapat menggantikan tatap muka selama 5 kali serta fasilitas e learning cukup menarik. Rekomendasi yang dapat kami tuliskan adalah adanya tim IT khusus Fakultas Pertanian sebagai tim asistensi permasalahan e learning secara terus menerus.

\section{Pelatihan E Learning}

Sosialisasi e-learning di Fakultas Pertanian dibagi dalam 2 (dua) sesi. Sesi pertama diisi oleh Dr. Rita Khathir, S.TP, M.Sc, dari Jurusan Teknik Pertanian Fakultas Pertanian (Pemenang Hibah E learrning Unsyiah 2018). Beliau pernah 
mendapatkan hibah e-learning dari Universitas Syiah Kuala. Sosialisasi dari Dr. Rita Khathir terdiri dari pengenalan tentang penggunaan e-learning, memaparkan manfaat e-learning dan peluang pengembangan kualitas perkuliahan melalui elearning. Sesi ini diajarkan teknik mengisi deskripsi mata kuliah yang meliputi materi, capaian pembelajaran, penilaian dan referensi. Konten yang terdapat pada e-learning juga dijelaskan yang terdiri dari uraian dalam bentuk Ms Word, power point presentation, dokumen dalam format pdf, tautan web, animasi, video dan gambar yang dapat digunakan untuk mendukung proses pembelajaran. Juga dijelaskan cara untuk mengupload bahan kuliah baik dalam bentuk power point presentation atau dalam format pdf.

Pada sesi kedua, materi disampaikan oleh dr. Tristia Rinanda dari Fakultas Kedokteran Universitas Syiah Kuala (Pemenang Hibah elearning dari Islamic Development Bank dan Project Implementation Unit (PIU) 7 in 1 UNSYIAH). Materi yang disampaikan dr.Tristia meliputi login dan membuat profile, pennggunaan fitur e-learning untuk transfer knowledge, komunikasi, survey, tugas, quis, ujian dan penilaian. Berbagai fitur yang dapat digunakan dalam e-learning Unsyiah adalah slide kuliah (ppt, pdf), jurnal yang relevan, buku ( $E$ book), gambar, video ajar, webpage, glossary dan berbagai fitur lainnya. Pemateri menjelaskan secara rinci cara menambahkan materi kuliah, video dan cara menggunakan glossary. Selain itu e-learning Unsyiah juga dapat digunakan untuk membuat survey dan mendapatkan feedback terhadap proses pembelajaran. Fasilitas e-learning Unsyiah juga dapat untuk melakukan tugas, quiz dan ujian dengan format yang berbeda sehingga dapat mencegah mahasiswa bekerjasama dalam menyelesaikan pertanyaan yang diberikan.

Dari kedua materi dari pelatih di atas kami merekomendasikan untuk diadakan pendampingan, sehingga ilmu yang sudah disosialisasikan tersebut menjadi sebuah keterampilan sehingga e learning mudah digunakan. Pelatihan yang berlangsung selama 2 sesi dari pagi sampai sore tersebut diharapkan menjadi awal untuk mengaktifkan ruang e learning pada mata kuliah yang diasuh para dosen di Fakultas Pertanian.

\section{Kesimpulan}

\section{Kesimpulan}

E learning belum efektif digunakan $(<10 \%)$ dan dosen Fakultas yang menggunakan (0,14\% dari Total Mata kuliah Di Unsyiah) hal ini dikarenakan dosen belum paham cara menggunakan e-learning sementara yang lainnya berpendapat kesulitan mengakses internet di lingkungan kampus, perlu waktu persiapan yang panjang dan seringnya terjadi pemadaman listrik. Jumlah dosen yang menggunakan hanya 6 orang dari 200 orang dosen Fakultas Pertanian, butuh peningkatan pemakai e learning hingga total pengguna minimal 20 persen dari total dosen (40 orang dosen). Jaringan internet telah baik, namun masih membutuhkan penataan dan tim teknologi informasi.

\section{Saran}

Perlu sosialisasi dan pelatihan berkala, pendampingan oleh tim dan adanya reward untuk meningkatkan penggunaan sistem ini serta aturan universitas yang mengikat.

\section{Ucapan Terima Kasih}

1. Kepada Lembaga Pengembangan Pendidikan dan Penjaminan Mutu (LP3M) atas dana Hibah Riset Aksi Universitas Syiah Kuala sesuai dengan Surat Perjanjian Pelaksanaan Hibah Riset Aksi Tahun Anggaran 2018 No: 16/UN11.LP3M/RA/SP2H/PNBP/2018.

2. Kepada Kepala dan staff Lembaga Teknis Teknologi Informasi dan Komunikasi (TIK) Unsyiah atas bantuan pengumpulan data.

\section{Daftar Pustaka}

[1] Peraturan Rektor Universitas Syiah Kuala No. 1 Tahun 2018.

[2]Peraturan Menteri Riset, Teknologi, dan Pendidkan Tinggi Republik Indonesia No. 44 Tahun 2015.

[3] Rencana Strategi Universitas Syiah Kuala Tahun 2015-2019

[4] Wawancara langsung ke UPT TIK Universitas Kuala Maret 2018

[5] N.S. Hanum. Keefektifan e-learning sebagai media pembelajaran (studi evaluasi model pembelajaran e-learning SMK Telkom Sandhy Putra Purwokerto). Jurnal Pendidikan Vokasi. Universitas Negeri Yogyakarta. Vol. 3 No. 1. Feb 2013. pp.90-102.

[6]Silahuddin. Penerapan E learning dalam Inovasi Pendidkan. Jurnal IImiah Pendidikan Elektro. Universitas Islam ArRaniry. CIRCUIT Vol. 1 No. 1 Juli 2015. Pp. 48-59.

[7] Silahuddin. Media Teknologi dan Implikasinya dalam Pengembangan Pendidikan. Jurnal IImiah Pendidikan Elektro. Universitas Islam ArRaniry. CIRCUIT Vol. 2 No. 1 Juli 2016. Pp. 199-207. 
Seminar Nasional Instrumentasi, Kontrol dan Otomasi (SNIKO) 2018

Bandung, Indonesia, 10-11 Desember 2018 